\title{
Severidad y extensión de incendios mediante índice de calcinación en las reservas indígenas de Salitre y Cabagra (Costa Rica)
}

\author{
Rubén Martínez Barbáchano \\ Escuela de Geografía. Universidad de Costa Rica. San José, Costa Rica ruben.martinezbarbachano@ucr.ac.cr
}

RESUMEN

Los incendios forestales constituyen un grave problema socio-ambiental durante los meses secos en las reservas indígenas del sur de Costa Rica (cordillera de Talamanca). La combinación de factores antrópicos (quema de pastos) con factores naturales (descenso de las precipitaciones, elevada insolación y vientos) generan anualmente las condiciones óptimas para la propagación de incendios cuyo impacto puede evaluarse en intensidad y extensión mediante imágenes satelitales. Las imágenes Sentinel 2, del programa Copérnico de la Agencia Espacial Europea, cuentan con información en el espectro del infrarrojo medio (entre 2100 y 2280 nanómetros) lo que permite mapear la extensión de dichos incendios a una resolución de 20 metros por píxel. La utilización de un índice de calcinación basado en el infrarrojo medio permitió mapear la extensión e intensidad de los incendios forestales ocurridos entre finales de febrero e inicios de marzo de 2020 en las reservas indígenas de Salitre y Cabagra (Buenos Aires de Puntarenas, Costa Rica).

Palabras clave: Incendios, teledetección, índice de calcinación normalizada, infrarrojo medio, Sentinel, Salitre, Cabagra

\begin{abstract}
Forest fires are a serious socio-environmental problem during the dry months on the indigenous reserves in southern Costa Rica (Talamanca mountain range). The combination of anthropic (pasture burning) and natural (decreasing precipitation, high sunshine and winds) factors generates annually optimum conditions for fires spreading the impact of which can be evaluated in intensity and range through satellite imagery. Sentinel 2 imagery, from the European's Space Agency (ESA) programme Copernicus, has information in the mid-infrared bandwidth (from 2100 to 2280 nanometers) that maps the the extent of those forest fires with resolution of 20 meters per pixel. The use of a burning index based on the mid-infrared allowed forest fires intensity and extension to be mapped on wildfires occurred in the end of February or early March of 2020, on the Salitre and Cabagra indigenous reservations (Buenos Aires de Puntarenas, Costa Rica).
\end{abstract}

Key words: Wildfires, remote sensing, normalized burn index, mid-infrared, Sentinel, Salitre, Cabagra

\section{Introducción}

La quema de pastizales y los consiguientes incendios forestales constituyen una grave amenaza socio-ambiental en las reservas indígenas del sur de Costa Rica. Se trata de un fenómeno recurrente, que se repite todos los años durante la estación menos lluviosa (meses de enero, febrero y marzo) en la vertiente del Pacífico de la cordillera de Talamanca, en el sur del país. Los estudios referentes al uso del fuego en las reservas indígenas del área de Talamanca han sido ampliamente estudiados, con un sistema de roza y quema de pasto que generalmente no excede la hectárea de superficie, con una ronda alrededor de la parcela para que el fuego no se extienda al resto del bosque (Borge, C. y Castillo, R. 1997). Algunas hipótesis permiten relacionar la abundancia de incendios con la expansión de las tierras agrícolas en las fronteras e interior de los territorios indígenas por parte de finqueros no-indígenas (Consejo Universitario, 2017). Sin embargo, el uso del fuego como método de control de malezas por parte de los pobladores indígenas, es conocido y constituye un riesgo para el propio territorio 
indígena y el área protegida colindante en la parte alta de la cordillera; el Parque Internacional La Amistad (Villegas Rodríguez, G. y González Brenes, F. 2017). Por otra parte, en la reserva indígena de Salitre el fuego para el control de malezas conduce al agotamiento del suelo y deja las parcelas sin capacidad para producir (Castillo-Rojas, K. M. 2020).

2020 registró el mayor número de incendios forestales desde el año 2000, según datos publicados por el Sistema Nacional de Áreas de Conservación (SINAC el 16 de junio de 2020. Sin embargo, el área total afectada por los incendios no fue muy grande (gráfico 1) ya que la mayoría fueron incendios de pequeña extensión. En total, 791 hectáreas de áreas silvestres protegidas, un promedio de 13 por incendio.

CUADRO 1.

Evolución de la superficie forestal afectada por incendios en Áreas Silvestres Protegidas

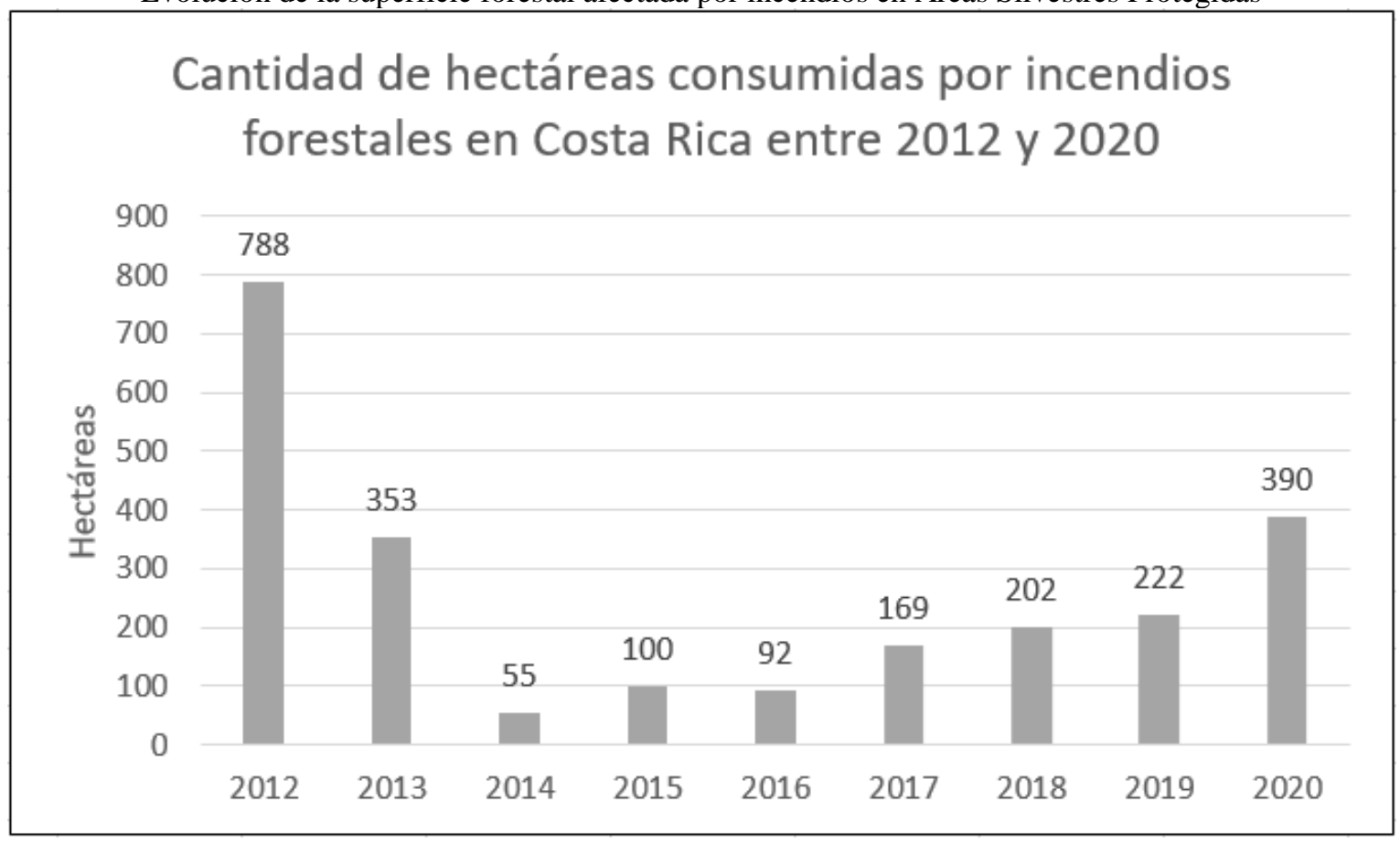

Fuente: Elaboración propia a partir de datos del SINAC

La teledetección constituye una herramienta de gran utilidad para caracterizar la severidad de los incendios dado que el proceso de combustión supone un descenso de la reflectividad en las regiones del visible y del infrarrojo cercano y un aumento en el infrarrojo medio de onda corta (Montorio et al., 2014).

La utilización de recursos satelitales en la investigación y monitoreo de los incendios en Costa Rica ha tenido múltiples aplicaciones en Guanacaste, por ejemplo, durante 1997 (año afectado por el fenómeno climático del Niño) Alfaro et al (1999) exploraron las capacidades del satélite GOES en la detección de puntos calientes asociados a incendios forestales. Más recientemente, Vargas (2016) analizó la dinámica de afectación y la recurrencia de los incendios forestales entre 1997 y 2015 en el bosque seco mediante el uso de imágenes Landsat. El presente estudio se basa en la aplicación de una metodología propia de la teledetección en el estudio del impacto y extensión del fuego en las reservas indígenas de Salitre y Cabagra, mediante la aplicación del índice de calcinación normalizada (dNBR) en los primeros meses del año 2020. Se trata del índice más extensamente usado para caracterizar la severidad de un incendio, y está basado en el índice NBR (Normalized Burn Ratio), propuesto por López y Caselles (1991).

El índice normalizado de severidad de incendios se ha mostrado muy útil para determinar superficies quemadas y el nivel de severidad del incendio (Llorens, R. et al. 2020). Incluso, la posibilidad de combinar imágenes del sensor Landsat 8 (de la NASA) con Sentinel 2 (de la Agencia Espacial Europea) para la realización de este 
índice se demostró factible en ecosistemas mediterráneos, con niveles de precisión superiores a 0,7 (Quintano, C. y Fernandez-manso. 2018).

Entre las limitaciones de este tipo de índices caben mencionar la limitada resolución espacial (de 20 metros en el caso de Sentinel 2) la persistente cobertura nubosa (que limita la disponibilidad de imágenes) o la escasa fiabilidad de la información procedente de los estratos inferiores del dosel arbóreo y, particularmente, del suelo (Hudak et al., 2007).

\section{Materiales y Métodos}

\section{Área de estudio:}

El área de estudio abarca los límites de las reservas indígenas Bribri de Salitre y Cabagra, en el cantón de Buenos Aires, provincia de Puntarenas (Costa Rica).

Figura 2.

Mapa de localización de la zona de estudio (reservas indígenas de Salitre y Cabagra)

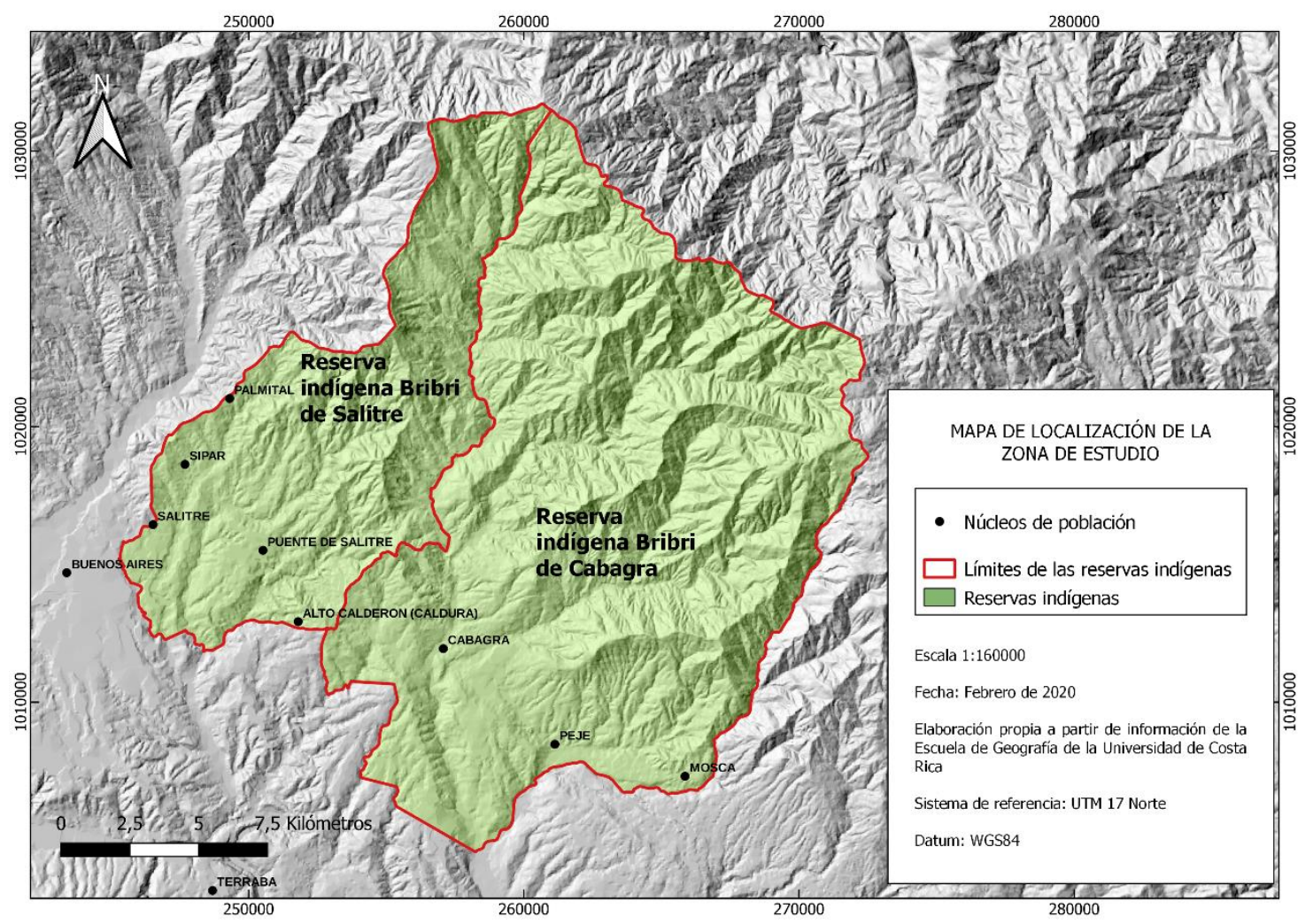

Fuente: Elaboración propia a partir de datos de la Escuela de Geografía de la Universidad de Costa Rica

El centro del área de estudio posee unas coordenadas de $9^{\circ} 12^{\prime} 00^{\prime \prime}$ de latitud norte y $83^{\circ} 08^{\prime} 50^{\prime \prime}$ de latitud oeste, con una altitud que va desde los 500 a los 2600 metros sobre el nivel del mar. El clima puede definirse como tropical lluvioso en las zonas bajas a templado lluvioso en las zonas altas, con un gradiente altitudinal que permite el desarrollo de las siguientes zonas de vida (de acuerdo a la clasificación de Holdridge):

- Bosque muy húmedo tropical de transición a premontano.

- Bosque pluvial premontano.

- Bosque pluvial montano bajo.

- Bosque pluvial montano. 
Figura 3.

Mapa de zonas de vida de Holdridge en la zona de estudio (reservas indígenas de Salitre y Cabagra)

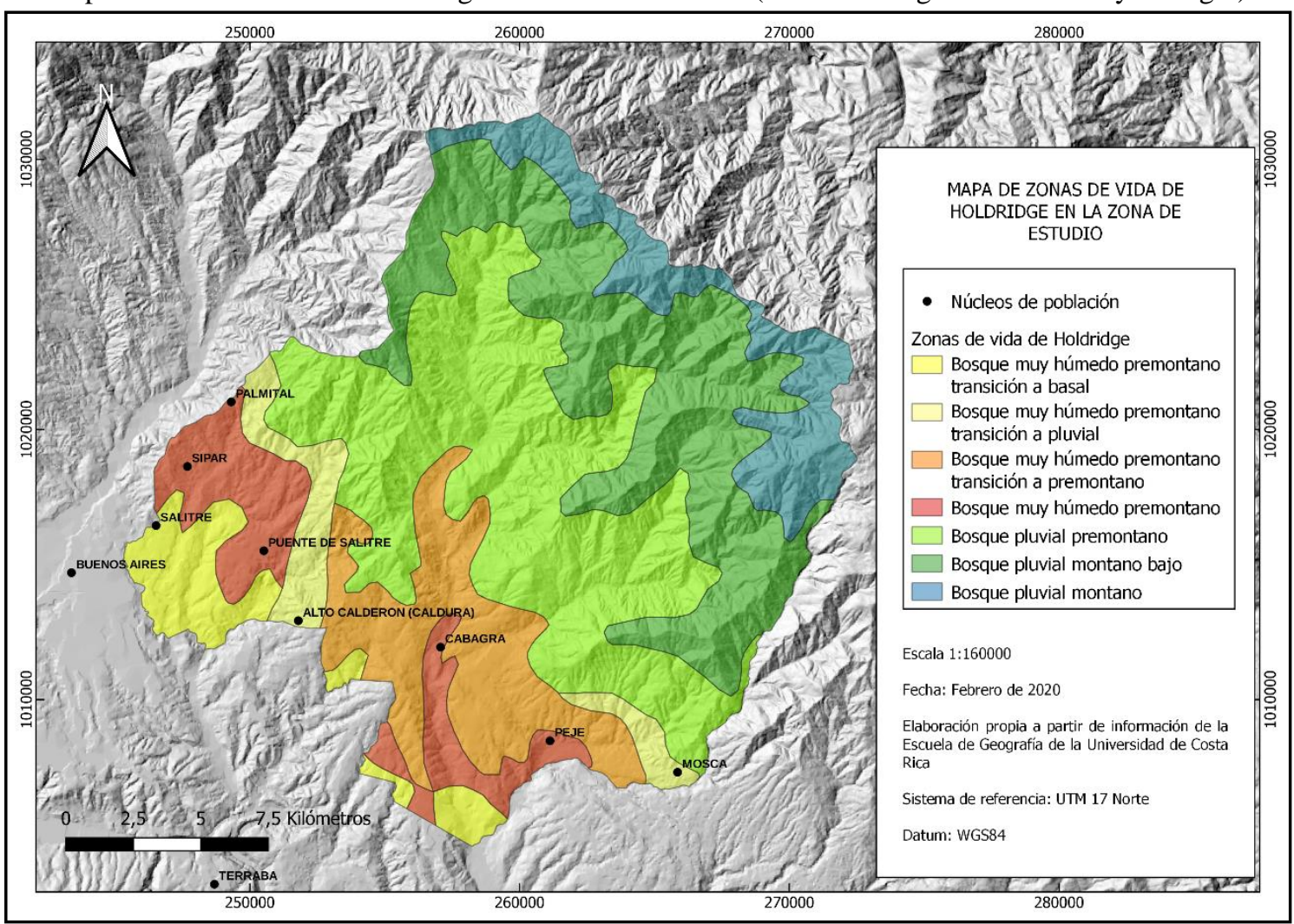

Fuente: Elaboración propia a partir de datos de la Escuela de Geografía de la Universidad de Costa Rica

Las precipitaciones oscilan entre los 1700 y 8000 milímitros anuales, con 3 meses considerados como secos en las zonas bajas y 2 en las zonas altas de ambas reservas.

\section{Fases del flujo de trabajo:}

La primera fase consistió en la descarga de las imágenes multiespectrales Sentinel 2, de la misión Sentinel 2 de la Agencia Espacial Europea (ESA) disponibles desde el año 2015 para el público de manera gratuita en el portal web; https://scihub.copernicus.eu/dhus/\#/home

Sentinel 2 proporciona imágenes multiespectrales con 13 bandas que cubren el espectro electromagnético desde los 0,443 $\mu \mathrm{m}$ hasta $2,19 \mu \mathrm{m}$, con tres niveles de resolución espacial; 10, 20 y $60 \mathrm{~m}$. La resolución temporal o frecuencia de paso es de 5 días, contando con las dos constelaciones (Sentinel 2A y Sentinel 2B).

\section{CUADRO 1.}

Bandas Sentinel 2, longitud de onda y resolución espacial

\begin{tabular}{|l|c|c|}
\hline \multicolumn{1}{|c|}{ Bandas Sentinel 2 } & $\begin{array}{c}\text { Centro de longitud de onda } \\
(\boldsymbol{\mu m})\end{array}$ & Resolución espacial (metros) \\
\hline Banda 1 (Aerosol costero) & 0,443 & 60 \\
\hline Banda 2 (Azul) & 0,49 & 10 \\
\hline Banda 3 (Verde) & 0,56 & 10 \\
\hline Banda 4 (Rojo) & 0,665 & 10 \\
\hline
\end{tabular}




\begin{tabular}{|l|c|c|}
\hline Banda 5 (Infrarrojo cercano) & 0,705 & 20 \\
\hline Banda 6 (Infrarrojo cercano) & 0,74 & 20 \\
\hline Banda 7 (Infrarrojo cercano) & 0,783 & 20 \\
\hline Banda 8 (Infrarrojo cercano) & 0,842 & 10 \\
\hline Banda 8A (Infrarrojo cercano) & 0,865 & 20 \\
\hline Banda 9 (Vapor de agua) & 0,9945 & 60 \\
\hline Banda 10 (Infrarrojo medio) & 1,375 & 60 \\
\hline Banda 11 (Infrarrojo medio) & 1,61 & 20 \\
\hline Banda 12 (Infrarrojo medio) & 2,19 & 20 \\
\hline
\end{tabular}

Fuente: Elaboración propia a partir de datos de la Agencia Espacial Europea (Copérnicus)

Para el proceso de selección de las imágenes se siguió un doble criterio:

- Escoger dos imágenes con un porcentaje de nubosidad próximo a cero.

- Escoger dos imágenes lo más próximas en fecha a los incendios ocurridos entre finales de febrero y mediados de marzo de 2020.

Las imágenes finalmente elegidas corresponden al 15 de febrero y al 06 de marzo de 2020, antes y después de los múltiples incendios que afectaron la zona. Las bandas utilizadas para el presente estudio fueron la 8 y la 12 (infrarrojo cercano y medio, respectivamente).

Otro aspecto importante a la hora de seleccionar las imágenes es el nivel de procesamiento del producto.

No fue necesario transformar los valores de los niveles digitales de las imágenes a reflectancia, dado que las imágenes Sentinel 2, en el nivel MSIL2A, están disponibles en el parámetro de reflectancia de superficie, lo que evita tener que efectuar correcciones atmosféricas, asumiendo de todos modos que la dispersión atmosférica es insignificante en las bandas infrarrojas utilizadas (en ausencia de nubes). Por otra parte, no fue necesario realizar corrección geométrica de las imágenes dado que ya están georreferenciadas y ortorrectificadas.

Los valores de índice de severidad de incendio (NBR) para cada píxel de ambas imágenes (15 de febrero y al 06 de marzo de 2020) se obtuvieron mediante la siguiente ecuación (1):

(1) $\quad \mathrm{NBR}=[\mathrm{B} 8-\mathrm{B} 12] /[\mathrm{B} 8+\mathrm{B} 12]$

Donde; B8 es la reflectancia en la banda 8 del infrarrojo cercano (de 0,785 a $0,899 \mu \mathrm{m}$ ) y B12 es la reflectancia en la banda 12 del infrarrojo de onda corta (de 2,1 a 2,28 $\mu \mathrm{m}$ ), tanto para la imagen pre-fuego ( 15 de febrero) como para la imagen post-fuego (06 de marzo). La herramienta utilizada para realizar el cálculo fue "calculadora raster" de QGIS, que permite realizar operaciones de álgebra de mapas.

Figura 4.

Índice de severidad de incendio anterior (izquierda) y posterior (derecha) a los incendios en el área de estudio. 

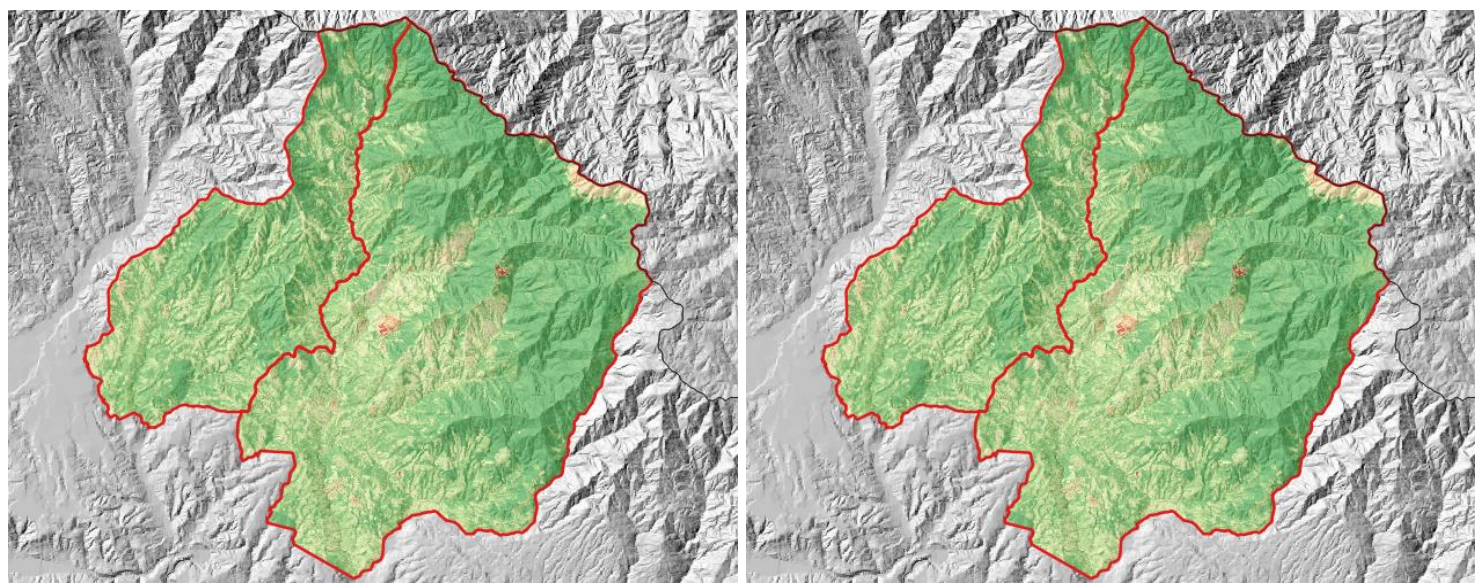

Fuente: Elaboración propia a partir de datos Sentinel 2, de la Agencia Espacial Europea.

Los valores del índice de severidad de incendio (dNBR) fueron propuestos por Key y Bensson (2006). Están basados en el cambio temporal entre las imágenes pre- y post-fuego y fueron calculados utilizando la ecuación (2).

$$
\mathrm{dNBR}=(\mathrm{NBR} \text { pre }-\mathrm{NBR} \text { post })
$$

Los rangos de clasificación (ver cuadro 2) son flexibles y no están exentos de valores extremos, eventualmente provocados por nubes u otros elementos susceptibles de introducir anomalías (Key, C.H., Benson, N.C. 2006.).

Cuadro 2.

Diferentes grados de severidad de incendio

\begin{tabular}{|c|c|c|}
\hline \multirow{2}{*}{ Clasificación de la severidad del incendio } & \multicolumn{2}{|c|}{ Rango de severidad del incendio } \\
\hline & Valor mínimo & Valor máximo \\
\hline Área sin quemar & $-0,1$ & 0,99 \\
\hline Área quemada de baja gravedad & 0,1 & 0,269 \\
\hline Área quemada de baja/moderada gravedad & 0,27 & 0,439 \\
\hline Área quemada de moderada/alta gravedad & 0,44 & 0,659 \\
\hline Área quemada de gravedad alta & 0,66 & 1,3 \\
\hline
\end{tabular}

Fuente: Elaboración propia a partir de los rangos de severidad propuestos por Key, C.H., Benson (2006).

Valores por debajo del umbral de $-0,1$ indican crecimiento y recuperación de la cobertura vegetal, por lo que no fueron considerados en este estudio.

Ética, conflicto de intereses y declaración de financiamiento: el autor declara haber cumplido con todos los requisitos éticos y legales pertinentes, tanto durante el estudio como en el manuscrito; que no hay conflictos de interés de ningún tipo, y que todas las fuentes financieras se detallan plena y claramente en la sección de agradecimientos. Asimismo, están de acuerdo con la versión editada final del documento. El respectivo documento legal firmado se encuentra en los archivos de la revista.

Ethical, conflict of interest and financial statements: the author declare that they have fully complied with all pertinent ethical and legal requirements, both during the study and in the production of the manuscript; that there are no conflicts of interest of any kind; that all financial sources are fully and clearly stated in the acknowledgements section; and that they fully agree with the final edited version of the article. A signed document has been filed in the journal archives.

\section{Resultados}

Figura 5 . 
Mapa de severidad de los incendios en febrero de 2020 para el área de estudio

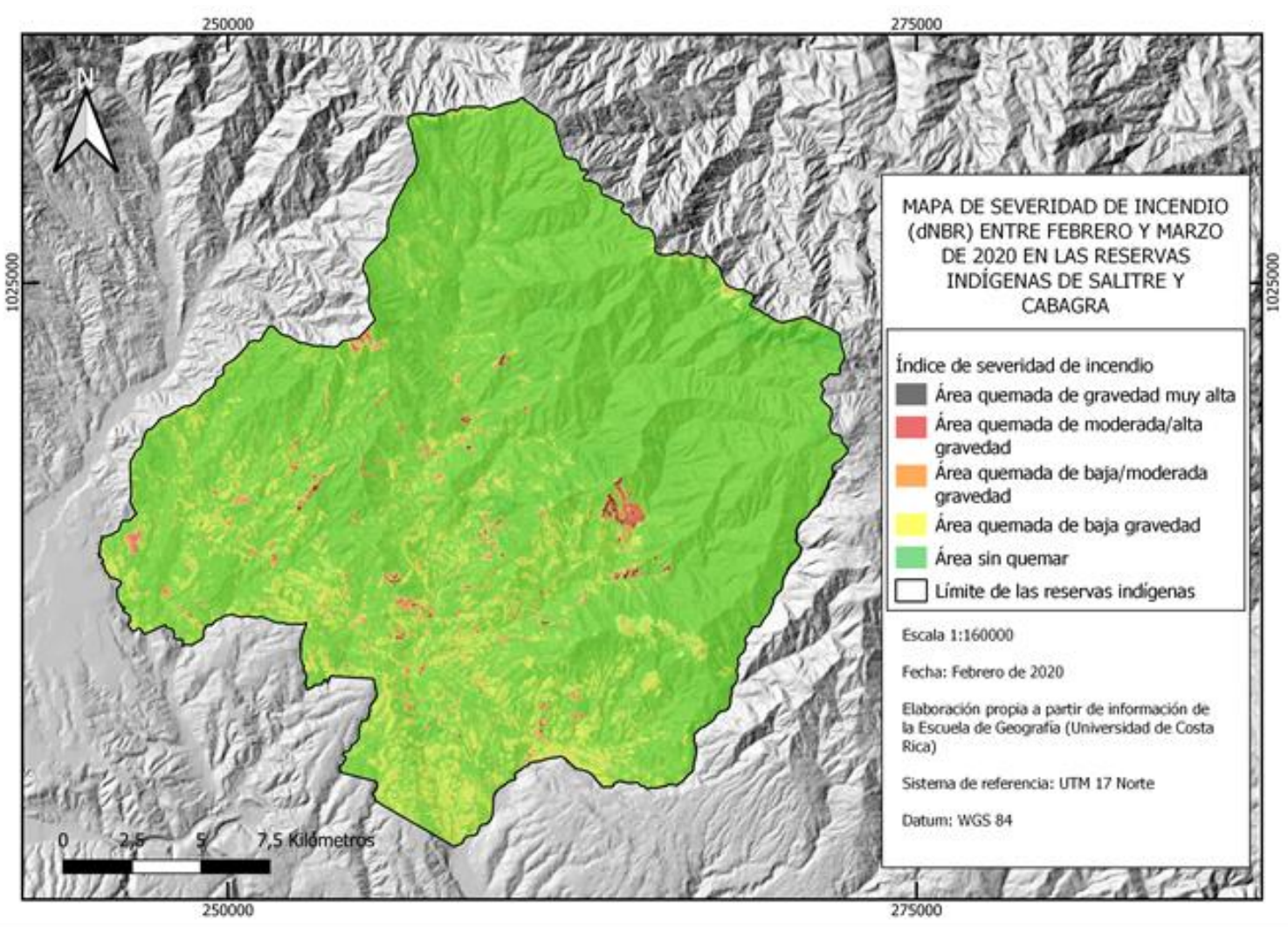

Fuente: Elaboración propia a partir de datos Sentinel 2, de la Agencia Espacial Europea.

Se procedió a vectorizar la capa ráster obtenida en el paso anterior, mediante la herramienta de QGIS "Píxeles ráster a polígonos", con el objetivo de obtener una estimación en hectáreas de la superficie quemada con sus diferentes grados de severidad (figura 5). El resultado se muestra en el cuadro 3.

Cuadro 3.

Superficie quemada por grado de severidad

\begin{tabular}{|c|c|}
\hline Clasificación de la severidad del incendio & Hectáreas afectadas \\
\hline Área sin quemar & 34058,192 \\
\hline Área quemada de baja gravedad & 4864,5 \\
\hline Área quemada de baja/moderada gravedad & 496,033 \\
\hline Área quemada de moderada/alta gravedad & 393,943 \\
\hline Área quemada de gravedad muy alta & 101,257 \\
\hline
\end{tabular}

Fuente: Elaboración propia a partir de los rangos de severidad propuestos por Key, C.H., Benson (2006).

Una representación del área de estudio con toda la superficie afectada (en mayor o menor grado) nos ofrece una imagen muy distinta (figura 6). Se trata de un área de 5855,7 hectáreas.

Figura 6.

Mapa de extensión de las áreas con algún nivel de afectación por incendios en febrero de 2020 para el área de estudio 


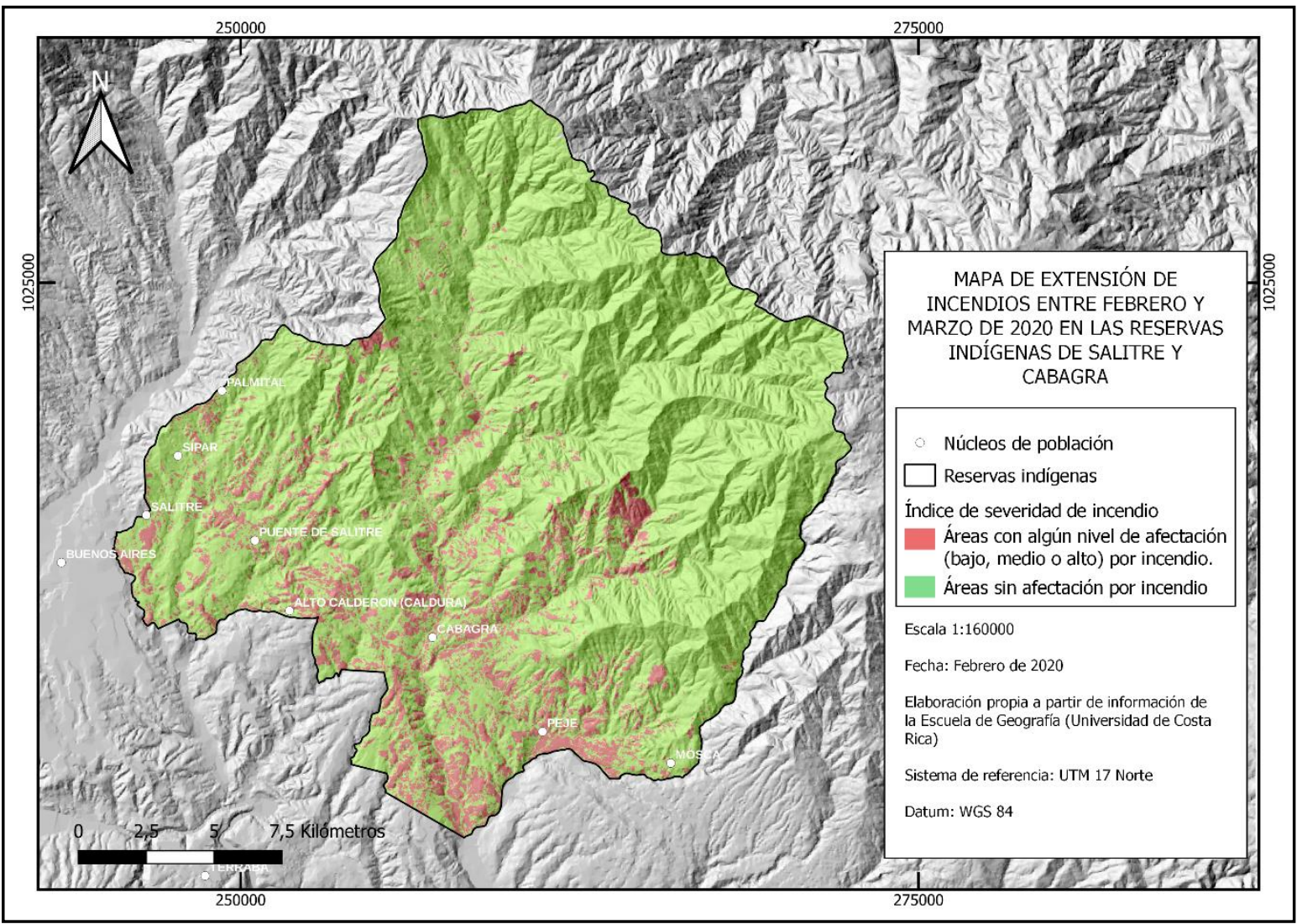

Fuente: Elaboración propia a partir de datos Sentinel 2, de la Agencia Espacial Europea.

Por último, se comparó la extensión de todas las áreas con algún nivel de afectación con las zonas de vida de Holdridge, para valorar qué ecosistemas resultaron más afectados (figura 7).

Figura 7.

Mapa de extensión de las áreas con algún nivel de afectación por incendios en febrero de 2020 en relación con las zonas de vida de Holdridge 


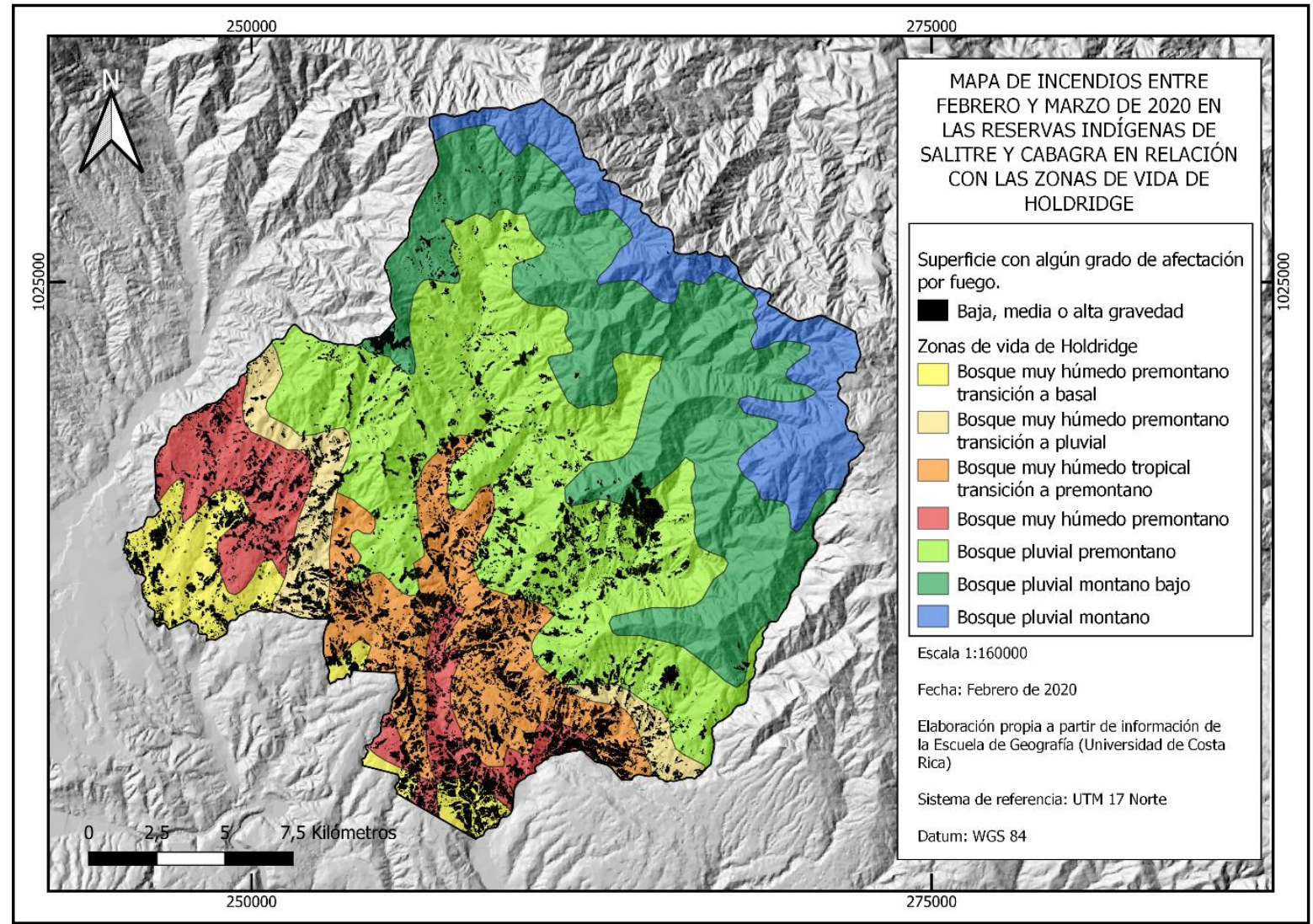

Fuente: Elaboración propia a partir de datos Sentinel 2, de la Agencia Espacial Europea

\section{Discusión}

El uso de índices de calcinación para la evaluación de la extensión e intensidad de los incendios permite obtener una valoración integral y detallada del impacto de este tipo de eventos desde un punto de vista geográfico. La metodología de álgebra de mapas aplicada a imágenes satelitales gratuitas del proyecto Copérnicus permitió mapear los incendios forestales ocurridos entre el 15 de febrero y el 06 de marzo de 2020 en las reservas indígenas Bribri de Salitre y Caraigres. La aplicación del índice de severidad de incendios (dNBR) permitió concluir que algo menos de un $1 \%$ de las reservas sufrió incendios de severidad muy grave, un $1 \%$ aproximadamente fueron de severidad baja y moderada a grave, y un $12 \%$ fue de baja severidad. El restante 86 $\%$ fue área no afectada en ningún grado por los incendios forestales.

Los focos de mayor extensión afectaron fundamentalmente a la parte central y meridional de las reservas, en algunos casos cercanos a núcleos de población, como los casos de Cabagra, Alto Calderón y Salitre (figura 6).

Cabe resaltar que, desde un punto de vista biogeográfico, las zonas de vida de Holdridge más afectadas por los incendios (en extensión) fueron el bosque muy húmedo premontano transición a basal, el bosque muy húmedo premontano y el bosque muy húmedo tropical transición a premontano. Sin embargo, desde el punto de vista de la severidad de los incendios, la zona que tuvo una mayor superficie con severidad grave por incendio fue el bosque pluvial premontano, mientras que el bosque pluvial montano no se vio afectado (figura 7). Hay que señalar, no obstante, que las zonas de vida de Holdridge hacen referencia a la vegetación potencial, no a la vegetación real en el momento de estudio. De hecho, la mayor parte de las áreas afectadas con un grado de severidad medio o alto fueron pastizales o zonas arbustivas de origen antrópico. 
El uso de las imágenes Sentinel 2 y especialmente las bandas 8 (infrarrojo cercano NIR) y la banda 12 (onda corta SWIR) permiten mapear la severidad de un incendio para unidades mayores o iguales a $400 \mathrm{~m}^{2}$. Esta escala de análisis viene condicionada por la resolución espacial de estas imágenes, de 20 metros por píxel. En todo caso, la presente metodología permite estimar la severidad del fuego a una escala de actuación intermedia y posibilita a los gestores forestales una mejor planificación de sus actuaciones post-incendio. Además, esta técnica permite estimar el impacto de los incendios en lugares inaccesibles o con dificultades de movimiento, acortando los periodos de toma de datos en campo.

Una variable a tener en cuenta en futuros análisis mediante la presente metodología, es la magnitud del fenómeno El Niño-Oscilación del Sur (ENOS) que se caracterizó por permanecer en una fase de neutralidad durante los dos meses analizados.

\section{Agradecimientos}

Por el respaldo para el desarrollo de este estudio, el autor agradece a la Escuela de Geografía de la Universidad de Costa Rica por la información sobre recursos cartográficos digitales ofrecidos, como capas vectoriales y modelos digitales del terreno.

\section{Referencias}

ALFARO, R., FERNANDEZ, W., \& CONNELL, B. Detection of the forest fires of April 1997 in Guanacaste, Costa Rica, using GOES-8 images. International Journal of Remote Sensing, 20(6), 1189-1195, 1999. Disponible en <https://www.tandfonline.com/doi/abs/10.1080/014311699212948 >Acceso en: 07 mayo de 2020.

Borge Carvajal, C., \& Castillo, R. (1997). Cultura y conservación en la Talamanca indígena. (pp. 132-135). Editorial UNED Costa Rica. (pp. 65).

Castillo-Rojas, M. (2020). Agroforestería como alternativa de desarrollo sostenible en el territorio indígena de Salitre, zona de amortiguamiento del Parque Internacional la Amistad. Revista Espiga, 19 (39), 63-76.

Consejo Universitario de la Universidad de Costa Rica (2007). Informe Final de la Comisión Especial de Salitre. (pp. 8).Hudak, A.T., Morgan, P., Bobbitt, M.J., Smith, A.M.S., Lewis, S.A., Lentile, L.B., Robichaud, P.R., Clark, J.T., McKinley, R.A. 2007. The relationship of multispectral satellite imagery to immediate fire effects. Fire Ecology, 3, 64-90. https://doi. org/10.4996/fireecology.0301064.

Key, C., Benson, N. (2005). Landscape Assessment: Remote Sensing of Severity, the Normalized Burn Ratio and Ground Measure of Severity, the Composite Burn Index. FIREMON: Fire effects monitoring and inventory system USDA Forest Service, Rocky Mountain Res. Station 164.

Key, C.H., Benson, N.C. 2006. Landscape Assessment (LA). In: Lutes, D.C., Keane, R.E., Caratti, J.F., Key, C.H., Benson, N.C., Sutherland, S., \& Gangi, L.J. (eds,). FIREMON: Fire effects monitoring and inventory system. USDA Forest Service, Rocky Mountain Research Station. Gen. Tech. Rep. RMRSGTR-164-CD, 1-55. 
Quintano, C. \& Fernandez-manso. (2018). Combination of Landsat and Sentinel-2 MSI data for initial assessing of burn severity. International Journal of Applied Earth Observation and Geoinformation. 64. 221-225. 10.1016/j.jag.2017.09.014.

Llorens, Rafael \& Sobrino, Jose \& Fernández Filgueira, Cristina \& Fernández-Alonso, José \& Vega, José. (2021). A methodology to estimate forest fires burned areas and burn severity degrees using Sentinel2 data. Application to the October 2017 fires in the Iberian Peninsula. International Journal of Applied Earth Observation and Geoinformation. 95. 102243. 10.1016/j.jag.2020.102243.

López García, María José \& Caselles, V. (1991). Mapping burns and natural reforestation using Thematic Mapper data. Geocarto International. 6. 31-37. 10.1080/10106049109354290.

Montorio Llovería, R., Pérez-Cabello, F., García- Martín, A., Vlassova, L., de la Riva Fernández, J. (2014). La severidad del fuego: revisión de conceptos, métodos y efectos ambientales. En: Arnáez Vadillo, J., González Sampériz, P., Lasanta Martínez, T., Valero Garcés, B.L. (ed.) Geoecología, cambio ambiental y paisaje: homenaje al profesor José María García Ruiz. Consejo Superior de Investigaciones Científicas, CSIC, Instituto Pirenaico de Ecología: Universidad de La Rioja.

Villegas Rodríguez, G. y González Brenes, F. (2017). Experiencias de manejo participativo de la biodiversidad en Costa Rica. Tomo 1. Agenda Indígena en el Territorio Indígena Cabagra. (pp. 141). Proyecto MAPCOBIO - JICA. ISBN: 978-9930-9405-4-9 